\title{
Study of the operation of the output filter of a single-phase series active power filter
}

\author{
Mihail Antchev', Vanjo Gourgoulitsov ${ }^{2}$, and Hristo Antchev ${ }^{3}$ \\ ${ }^{1}$ Section Power Electronics, Faculty of Electronic Engineering and Technologies, Technical University, Sofia, Bulgaria \\ ${ }^{2}$ College of Energy and Electronics, Technical University, Sofia, Bulgaria \\ ${ }^{3}$ Section Electrical Engineering and Electronics, Department of Metallurgical Technologies, Electrical Engineering and \\ Electronics, Faculty of Metallurgy and Mathematical Science, University of Chemical Technologies and Metallurgy, \\ Sofia, Bulgaria
}

\begin{tabular}{l} 
Article Info \\
\hline Article history: \\
Received Aug 28, 2020 \\
Revised Jan 19,2021 \\
Accepted Feb 2,2021 \\
\hline
\end{tabular}

\section{Keywords:}

Hysteresis voltage control Output capacitor Series active power filter

\begin{abstract}
In the article is presented a single-phase series active power filter (SFSAPF) designed to compensate the total harmonic distortion (THD) factor of the supply network voltage. Particular attention is paid to the work of the output capacitor of the passive filter, and dependencies for the design of the filter at hysteresis voltage control are presented. The value of the higher harmonics of the current through the filter capacitor is determined. A mathematical relationship between the voltage ripple of the capacitor, its value and the switching frequency is derived. As a result of the advanced research a methodology for designing the output filter of a single-phase serial active power filter has been proposed. The results from computer simulation and experiment are also given.
\end{abstract}

This is an open access article under the CC BY-SA license.

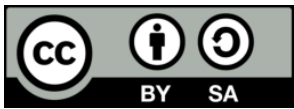

\section{Corresponding Author:}

Mihail Antchev

Section Power Electronics, Faculty of Electronic Engineering and Technologies

Technical University -Sofia

1000, Sofia, Bulgaria

Email: antchev@tu-sofia.bg

\section{INTRODUCTION}

The shunt and series active power filters are an effective and perspective means for solving the problems with the quality of electrical power [1]-[3]. Most commonly, series active power filters (SAPF) are used to improve the total harmonic distortion (THD) factor of the supply network voltage, used to power sensitive consumers [4]-[11]. In their control systems are used: sliding mode control [12], fuzzy logic control [13], [14] deadbeat control [15], monitoring of filter capacitor current [16], hysteresis control of the filter capacitor voltage or the load voltage [17], [18]. Newer control methods are also used, such as: based on perphase current calculation [19] and neural network control [20], [21]. Particular attention is paid to the accurate synchronization with the source voltage, as an overview of the main methods is done in [22].

The literature study regarding the features of the output filter shows that there are comparatively fewer studies dealing with the design features of the output passive $L C$ filter. In [23] is analyzed a new seriesparallel-resonant $L C L$ filter as a part of a shunt active power filter. In [24] there is an analysis of the operation of $L C L$ filter in the configuration also of a shunt active power filter. Taking into account the high frequency modulation, the values of the current through the filter capacitor as well as through the DC capacitor are defined. 
There is not a complete study of the operation of the passive $L C$ filter as part of a SAPF with hysteresis control of the filter capacitor voltage. This would have allowed the presentation of a methodology for its design.

Figure 1 shows the block diagram of a SFSAPF. Its purpose is to produce such a voltage $U_{A F}$ of the secondary winding of the transformer Tr, to compensate the higher harmonics of the voltage $U_{S}$ of the power source $\mathrm{AC}$, so that the load voltage $U_{L}$ has a sinusoidal shape.

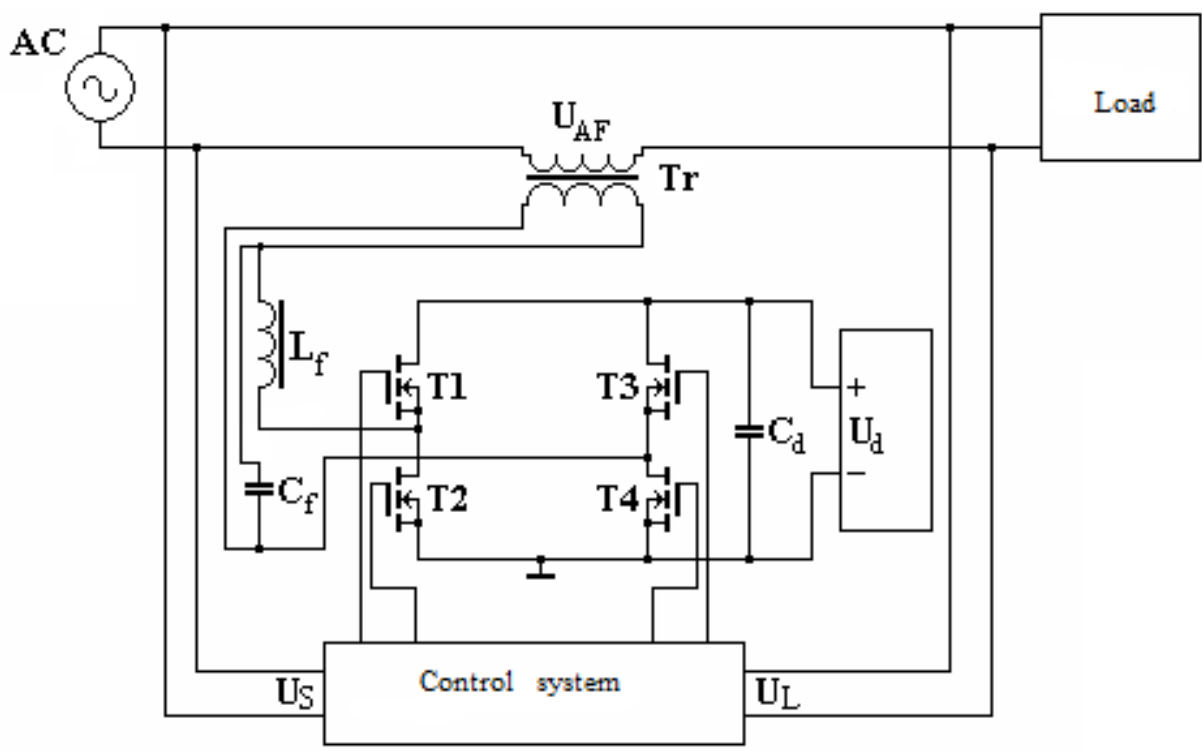

Figure1. Block diagram of a SPSAPF.

There are two features of the output capacitor $C_{f}$ work: 1 . The voltage on the capacitor contains higher harmonics, which must be in antiphase to their respective ones, contained in the supply network voltage curve. These harmonics determine the only one component of the root mean square (RMS) value of the current through the capacitor. In addition, the current also contains a high-frequency component as a result of hysteresis control. 2. In hysteresis control, the value of the capacitor $C_{f}$ and the output inductance $L_{f}$ depend on the hysteresis parameters and the switching frequency of the power devices.

The problem is that there is no comprehensive study of the specified features of the operation of the capacitor of the output filter. Tthere is no comprehensive metology for filter design. The purpose of this article is to present a study of these features, which is lacking in the specialized literature. The novelty in the work is in determining the relationship of the value of the capacitor with the RMS value of the higher harmonic current and voltage ripple. As a result, a new methodology for the design of the output filter has been proposed.

In the second part, a mathematical description is made, and are offered expressions in accordance with the two described features. The results from the computer simulation are presented in the second part. The third part shows the experimental results of the work of the SPSAPF with linear and nonlinear load.

\section{RESEARCH METHOD}

\subsection{Mathematical description}

It should be noted, that the curves in the form of the supply network voltage have different shape and character, so it is necessary to accept a certain approximation of this form. For the purposes of the analysis, connected with the first feature (determining the RMS value of the current through the capacitor), is accepted an approximation of the curve of the supply network voltage with trapezoidal shape, shown in Figure 2. It gets close to a common case in practice-load of the network with single-phase bridge uncontrolled rectifiers, which are non-linear loads and consume current around the maximums of the network voltage. As a result, voltage drops around its maximum value. 


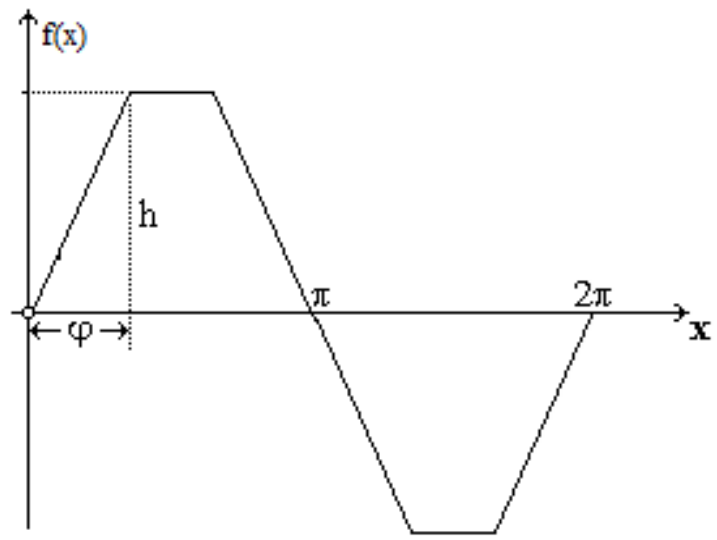

Figure 2. Approximation of the curve of the supply network voltage.

The decomposition of such a trapezoidal function in Fourier series is known:

$f(x)=\frac{4 \cdot h}{\pi \cdot \varphi} \cdot \sin (\varphi) \cdot \sin (x)+\frac{4 \cdot h}{\pi \cdot \varphi} \sum_{k=2}^{\infty} \frac{1}{(2 \cdot k-1)^{2}} \sin (2 \cdot k-1) \cdot \varphi \cdot \sin (2 \cdot k-1) \cdot x$

Therefore, for the THD factor, we obtain:

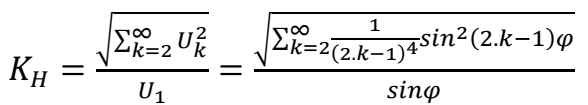

Figure 3 shows the corresponding graphical dependence for the interval $0.3 \leq \varphi \leq 1.0 \mathrm{rad}$. The sum is limited to $k=25$ in accordance with [25], [26].

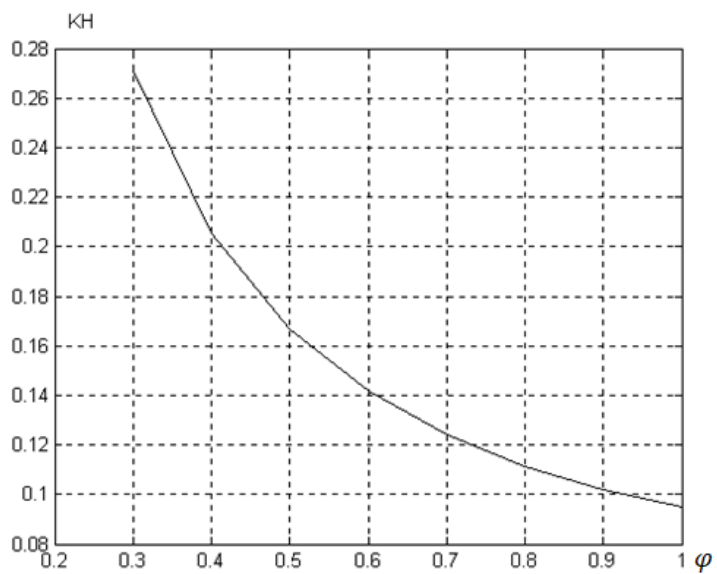

Figure 3. Graphical dependence according to expression (2)

In this way, it is possible to determine the amplitude values of the harmonics of the voltage on the output capacitor of the SAPF. These harmonics, added in antiphase to their respective ones to the curve of Figure 2, would make the voltage on the load sinusoidal with frequency of the first harmonic.

$$
U_{K m}=\frac{4 \cdot h}{\pi \cdot \varphi} \cdot \frac{1}{(2 \cdot k-1)^{2}} \cdot \sin (2 \cdot k-1) \cdot \varphi
$$

for $k=2,3 \ldots \ldots$ 
The maximum value of the current through the capacitor $C_{f}$ of the output filter for each of these harmonics will be:

$$
I_{C_{f k m}}=U_{K m} \cdot(2 \cdot k-1) \cdot \omega \cdot C_{f}
$$

for $k=2,3 \ldots \ldots$

Considering all the harmonics, the RMS value of the current through the filter capacitor $C_{f}$ will be:

$$
I_{C_{f R M S}}=\frac{2 . C_{f} \cdot h \cdot \omega \cdot \sqrt{2}}{\pi \cdot \varphi} \cdot \sqrt{\sum_{k=2}^{\infty} \frac{1}{(2 . k-1)^{2}}, \sin ^{2}(2 \cdot k-1) \cdot \varphi}
$$

The ratio of the RMS value of the current to the capacitor value at the frequency of the supply voltage $f=50 \mathrm{~Hz}$ is:

$$
\frac{{ }^{I} C_{f R M S}}{C_{f}}=\frac{200 \cdot \sqrt{2} \cdot h}{\varphi} \sqrt{\sum_{k=2}^{\infty} \frac{1}{(2 . k-1)^{2}} \cdot \sin ^{2}(2 \cdot k-1) \cdot \varphi}
$$

Figure 4 shows a set of features reflecting the above dependence at parameter $h$. The sum is limited to $k=25$ in accordance with $[25,26]$.

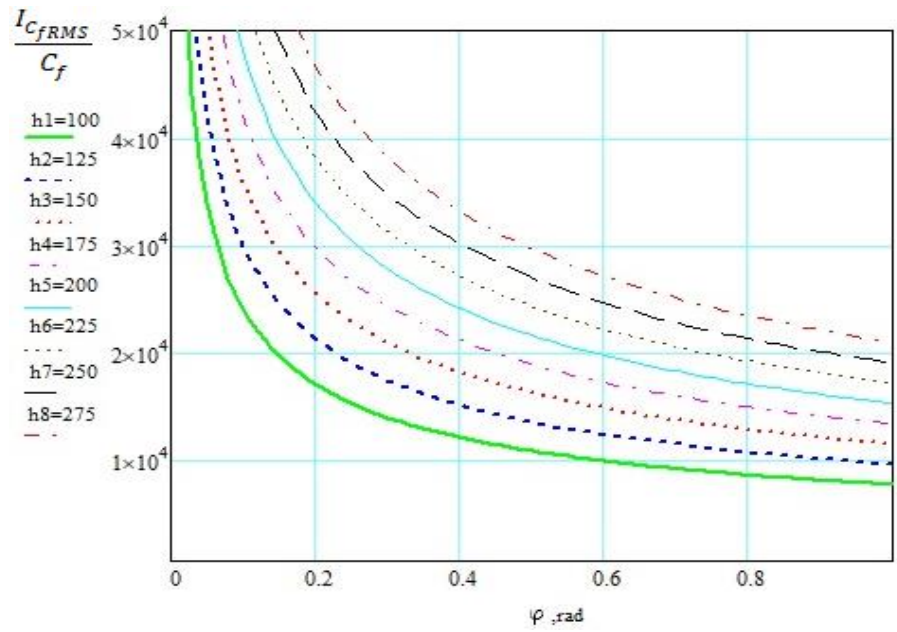

Figure 4. Set of features according to expression (6)

Depending on (6) the value of the capacitor is indicated and therefore it is necessary to perform an analysis to determine this value. In connection with the second feature (determining the value of the capacitor $C_{f}$ at hysteresis control), the time diagrams shown in Figure 5 are used.
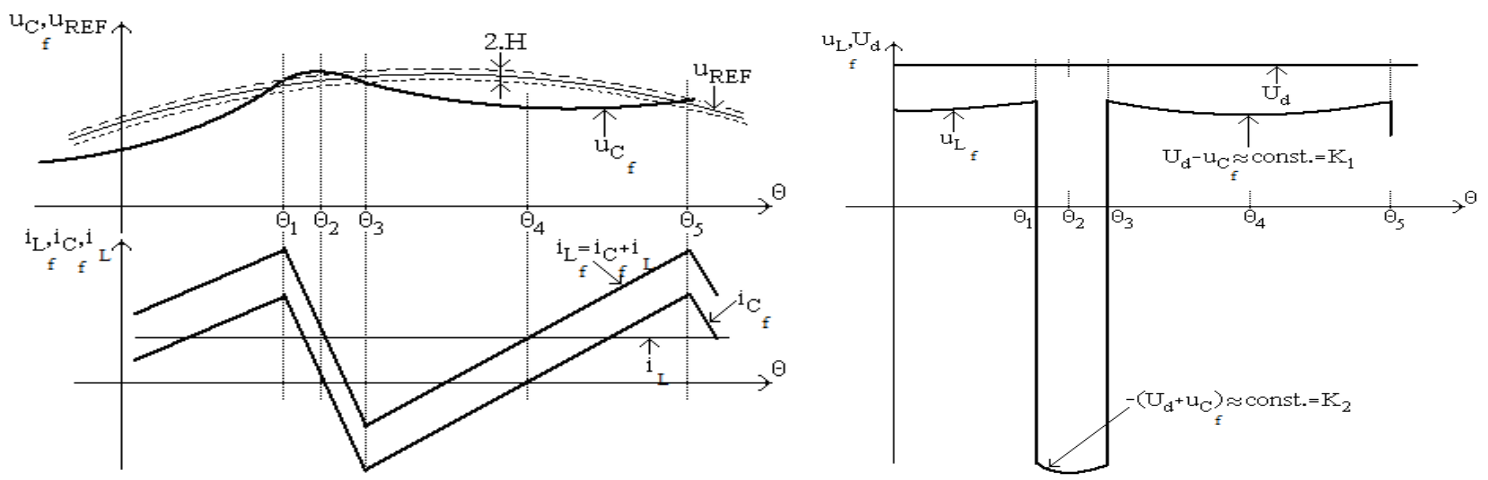

Figure 5. Time diagrams for hysteresis control of the voltage on capacitor $C_{f}$ 
The examination is made within one switching period $T=\theta_{5}-\theta_{1}$ of the power devices. This period is significantly shorter than the half-period of the network voltage. At moment $\theta=\theta_{1}$ the transistors from this diagonal of the bridge power circuit from Figure 1 are switched on, for which the voltage $u_{C_{f}}$ decreases, and at moment $\theta=\theta_{3}$-for which it increases. Since the filter $L_{f} C_{f}$ is a second-order unit, after the moment $\theta=\theta_{1}$ there is a certain increase in voltage, and after the moment $\theta=\theta_{3}$ - a decrease. Provided, that the voltage ripple on the capacitor $C_{f}$ is neglected, it can be assumed that the current through the inductor $L_{f}-i_{L f}$ changes in both intervals according to a linear law. At these intervals, voltage with approximately constant value $K_{2}$ is applied to $L_{f}$ for the interval $T-t_{O N}=\theta_{3}-\theta_{1}$, and $K_{1}$ for the interval $t_{O N}=\theta_{5}-\theta_{3}$. For the short duration of the period, the changes of current $i_{L_{f}}$ in both directions are equal, therefore:

$$
\left(U_{d}-u_{C_{f}}\right) \cdot t_{O N}=\left(U_{d}+u_{C_{f}}\right) \cdot\left(T-t_{O N}\right)
$$

After simplification, it follows (8):

$$
\frac{u_{C_{f}}}{U_{d}}=2 . \delta-1
$$

where

$$
\delta=\frac{t_{O N}}{T}
$$

Therefore, if the reference curve for the voltage of the capacitor $u_{C_{f}}(\theta)=u_{R E F}(\theta)$ is known, then the law of change of $\delta(\theta)$ is also known.

$$
\delta(\theta)=\frac{u_{R E F}(\theta)}{2 \cdot U_{d}}+\frac{1}{2}
$$

At hysteresis control, this reference curve is monitored with a definite hysteresis, where the capacitor voltage also contains high-frequency ripples, which are result of the switching with high frequency $f_{S}$. Based on these ripples, a way is sought to determine the value of the capacitor $C_{f}$. If the start of the coordinate system is translated at the moment $\theta_{2}$, the change of the capacitor voltage $u_{C_{f}}$ in the interval $\theta_{2}-$ $\theta_{3}$ can be found, ie.one part of the pulsation:

$$
\left|\Delta u_{C_{f}}^{\prime}\right|=\frac{1}{C_{f}} \cdot \int_{0}^{\frac{T-t_{O N}}{2}} \frac{\left|\Delta i_{C_{f}}\right|}{T-t_{O N}} \cdot t \cdot d t=\frac{1}{8 . C_{f}} \cdot\left|\Delta i_{C_{f}}\right| \cdot\left(T-t_{O N}\right)
$$

The rest of the pulsation can be found when translating the start of the coordinate system at the moment $\theta_{3}$ :

$$
\left|\Delta u_{C_{f}}^{\prime \prime}\right|=\frac{1}{C_{f}} \cdot \int_{0}^{\frac{t_{O N}}{2}} \frac{\left|\Delta i_{C_{f}}\right|}{t_{O N}} \cdot t \cdot d t=\frac{1}{8 \cdot C_{f}} \cdot\left|\Delta i_{C_{f}}\right| \cdot t_{O N}
$$

by summing (11) and (12), the whole pulsation can be found:

$$
\left|\Delta u_{C_{f}}\right|=\left|\Delta u_{C_{f}}^{\prime}\right|+\left|\Delta u_{C_{f}}^{\prime \prime}\right|=\frac{1}{8 . C_{f}} \cdot\left|\Delta i_{C_{f}}\right| \cdot \frac{1}{f_{S}}
$$

or

$$
\frac{\left|\Delta u_{C_{f}}\right|}{\left|\Delta i_{C_{f}}\right|}=\frac{1}{8 \cdot C_{f}} \cdot \frac{1}{f_{S}}
$$

The following design sequence may be recommended: The Total Harmonic Distortion (THD) factor of the supply network voltage $K_{H}$ and the maximum value of the load current $I_{L m}$ are known. 1. with known Total Harmonic Distortion (THD) factor of the supply network voltage $K_{H}$, from Figure 3 is determined the value of the angle $\varphi$.2. Expression (2) and value of $h$ (to approximate the supply voltage curve) are used to 
determine the RMS value of the higher harmonics. Based on (14), the value of the capacitor $C_{f}$ is determined by assuming values for $\Delta i_{C_{f}}$ (as a percentage of the maximum value of the load current $I_{L m}$ ) and $\Delta u_{C_{f}}$ (as a percentage of the RMS value of the higher harmonics). 3 . The RMS value of the capacitor current $I_{C_{f R M S}}$ at the value of $h$ from item 2. is determined from Figure 4. To this value is added the current with the high switching frequency $f_{S}=20 \mathrm{kHz}$. 4. The value of the inductance $L_{f}$ is determined, so that the resonant frequency of the filter $L_{f} C_{f}$ to be higher than the frequency of the highest harmonic being compensated, and lower than the switching frequency $f_{S}$. 5 . The value of the hysteresis $H$ as a percentage of $\Delta u_{C_{f}}$ is determined.

Example: It is known as a result of measurement: Total Harmonic Distortion (THD) factor of the supply network voltage $K_{H}=17 \%$ and maximum value of the load current $I_{L m}=10 \mathrm{~A}$. Approximate value of $h=290 \mathrm{~V}$.

1) For $K_{H}=17 \%$ from Figure 3 is reported $\varphi=0.5 \mathrm{rad}$.

2) From (2) and (1) the RMS value of the higher harmonics at $h=145 \mathrm{~V}$ is determined (the transformer $\mathrm{Tr}$ increases the voltage of the capacitor $C_{f} 2$ times $)-K_{H} . \sin \varphi=0.082 \rightarrow \frac{4.145}{\pi \cdot 0,5} .0 .082 \approx 30 \mathrm{~V} \cdot \Delta u_{C_{f}}=$ $0.6 \mathrm{~V} \rightarrow[(1-2 \%) .30], \Delta i_{C_{f}}=1 A \rightarrow\left[(5-10 \%) .2 . I_{L m}\right]$ is accepted, and the value of the capacitor at frequency $f_{S}=20 \mathrm{kHz} C_{f}=10 \mu \mathrm{F}$ is determined from (14).

3) From Figure 4 is determined $I_{C_{f R M S}}=165 \mathrm{~mA}$. To this value is added the current with the high switching frequency $f_{S}=20 \mathrm{kHz}$. The maximum value of the first high frequency voltage harmonic is equal to half the ripple $\Delta u_{C_{f}}$. Thus, the RMS value of the current through the capacitor $C_{f}$ with high frequency is $\frac{\Delta u_{C_{f}}}{2 \cdot \sqrt{2}} \cdot 2 \cdot \pi \cdot f_{s} \cdot C_{f}=\frac{0.6}{\sqrt{2}} \cdot \pi \cdot 20 \cdot 10^{3} \cdot 10 \cdot 10^{-6}=266 m A$.Or in general $I_{C_{f R M S}}=165 \mathrm{~mA}+$ $266 \mathrm{~mA} \approx 430 \mathrm{~mA}$.

4) The value of the inductance $L_{f}$ is related to the determined value of the capacitor $C_{f}$. To avoid possible resonance phenomena on the one hand, it is necessary the resonant frequency of the filter to be higher than the frequency of the highest harmonic, which is compensated (in this case the 25th). On the other hand, it must be significantly lower than the switching frequency of the power devices (in this case 20 $\mathrm{kHz}$ ). For these reasons, an appropriate value is $500 \mu \mathrm{H}$. At this case the resonant frequency of $L_{f} C_{f}$ is approximately $2.25 \mathrm{kHz}$. The RMS value of the current through the inductance is a sum of the RMS values of the current of the capacitor and the load, also taking into account the transformation coefficient of the output transformer $-I_{L_{f R M S}}=2 \cdot \frac{I_{L m}}{\sqrt{2}}+I_{C_{f R M S}} \approx 14.57 \mathrm{~A}$.

5) Hysteresis $H$ determination. The determination of the hysteresis value used to monitor the capacitor voltage is done on the base of the accepted value for $\Delta u_{C_{f}}$. It is recommended $2 . H=[(40-$ $\left.50 \%) \Delta u_{C_{f}}\right]$. In case of $(0.24-0.3) \mathrm{V}$.

\subsection{Computer simulation}

A study was performed by computer simulation of the operation of the SFSAPF at the thus set initial data and certain values in the above example. This is done with the ORCAD-PSPICE program. Figure 6 and Figure 7 show the results when a linear load (active-inductive) is connected to the power supply network. Figure 8 shows the results for a non-linear load for the power supply network-single-phase uncontrolled bridge rectifier with active-capacitive load.

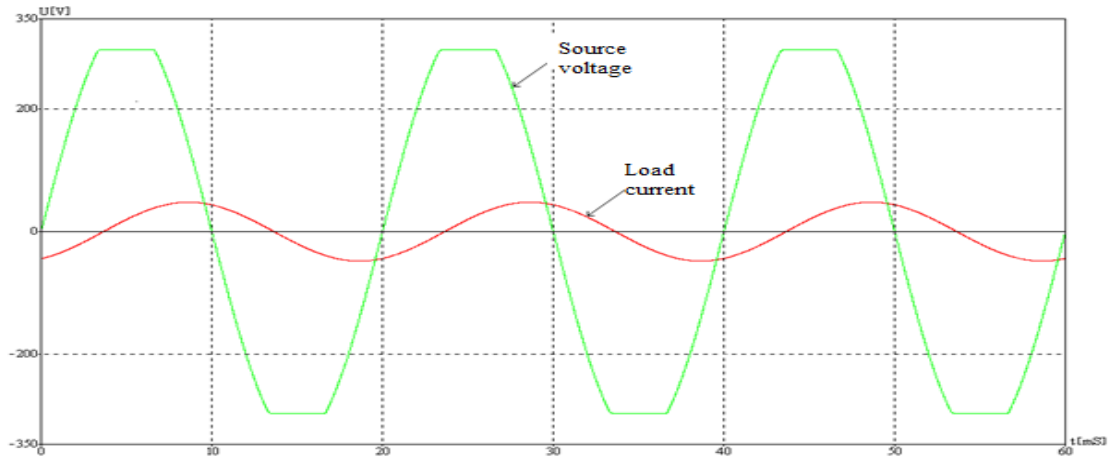

Figure 6. Voltage of the power supply network (and of the load) and load current in the absence of an SAPF. 


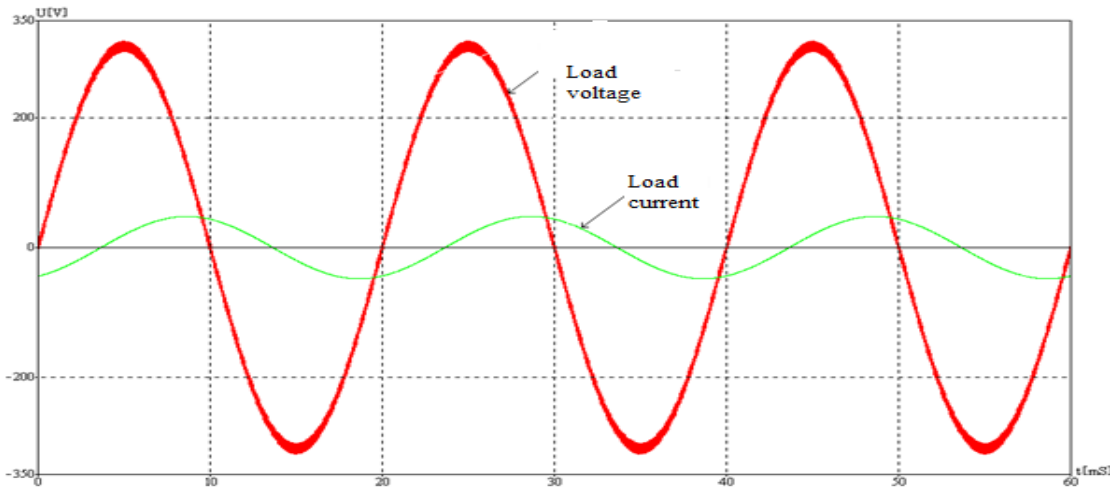

Figure 7. Load voltage and load current with SAPF on.

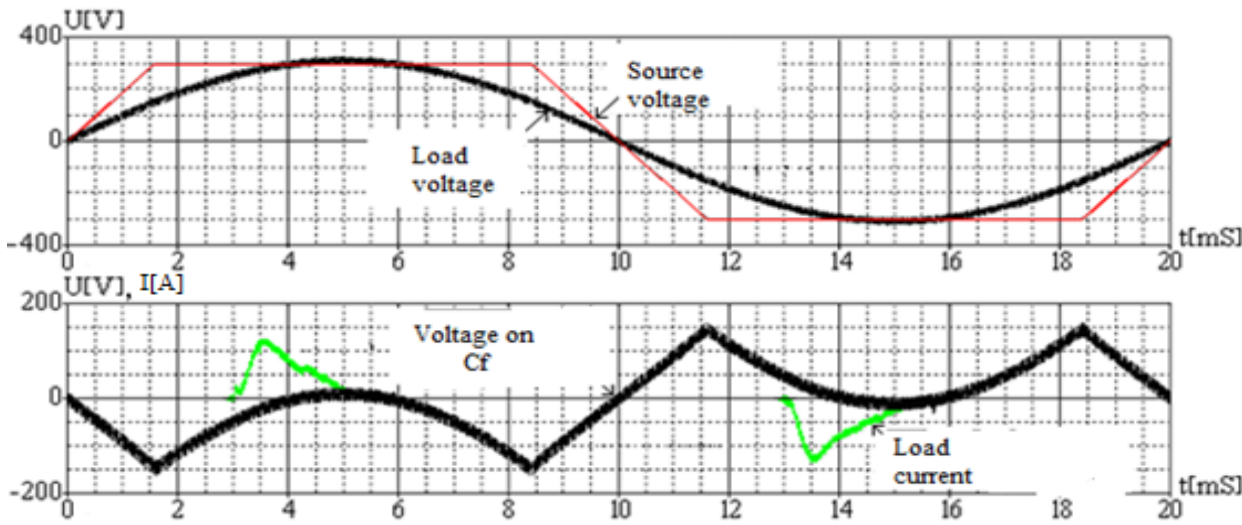

Figure 8. Results of the operation of the SAPF with non-linear load

\section{RESULTS AND DISCUSSION}

The results of the computer simulation have been confirmed experimentally. The corresponding oscillograms are shown in Figure 9 and Figure 10. The current in Figure 9 and Figure 10 was monitored with a 100: 1 current probe. The results of the experimental study confirm the results obtained from the computer simulation. Figure 11 shows the oscillograms with substantially nonlinear load-AC regulator with phase control.

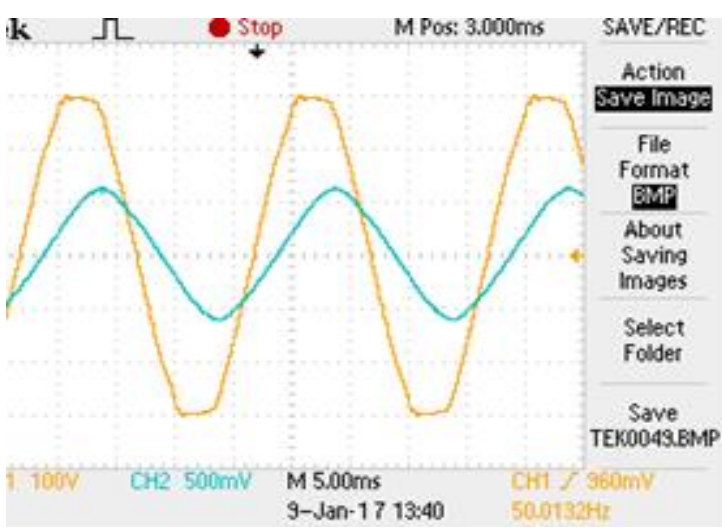

(a)

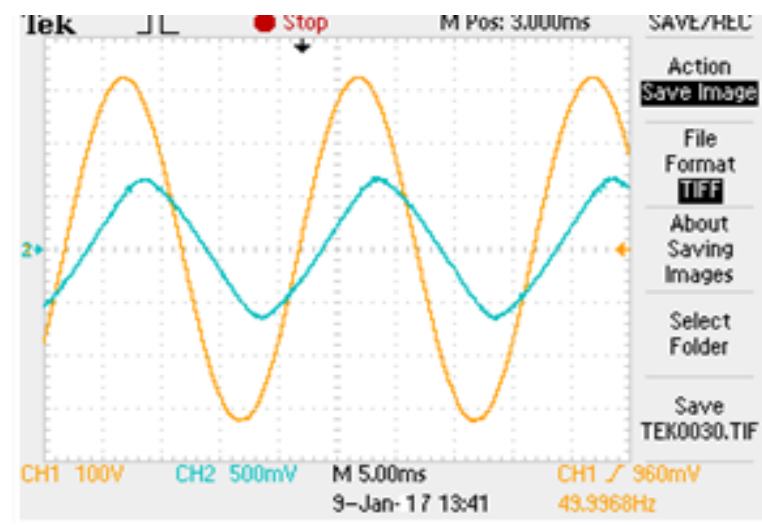

(b)

Figure 9. Results at active-inductive load: (a) load voltage and load current without SAPF; (b) load voltage and load current with SAPF on. 


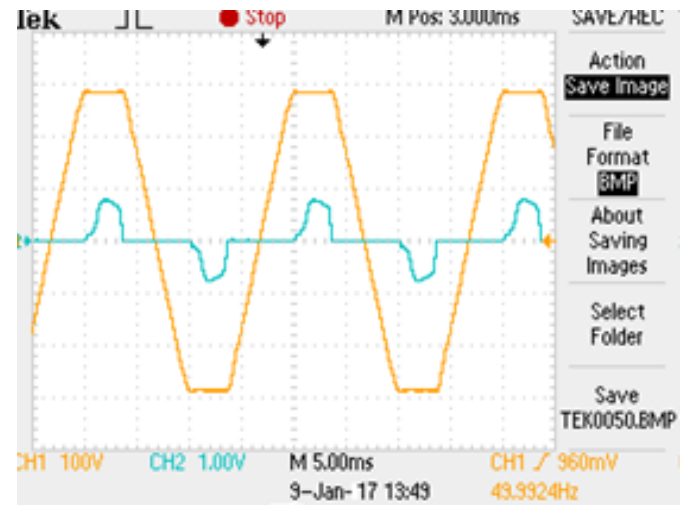

(a)

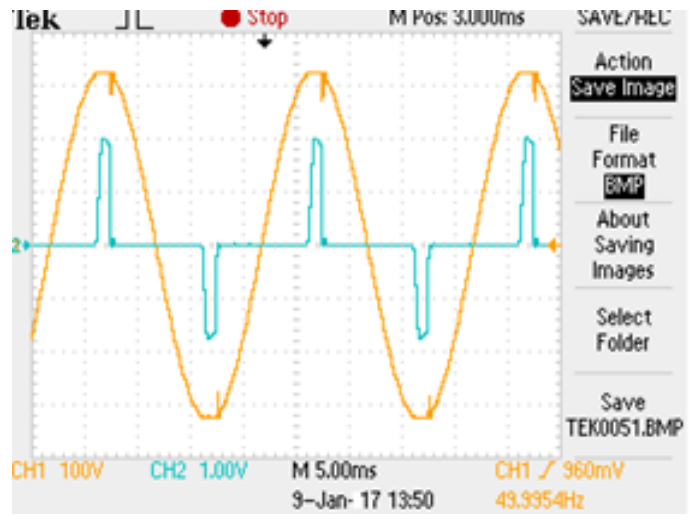

(b)

Figure 10. Results at nonlinear load-bridge rectifier with RC load: (a) load voltage and load current without SAPF; (b) load voltage and load current with SAPF on
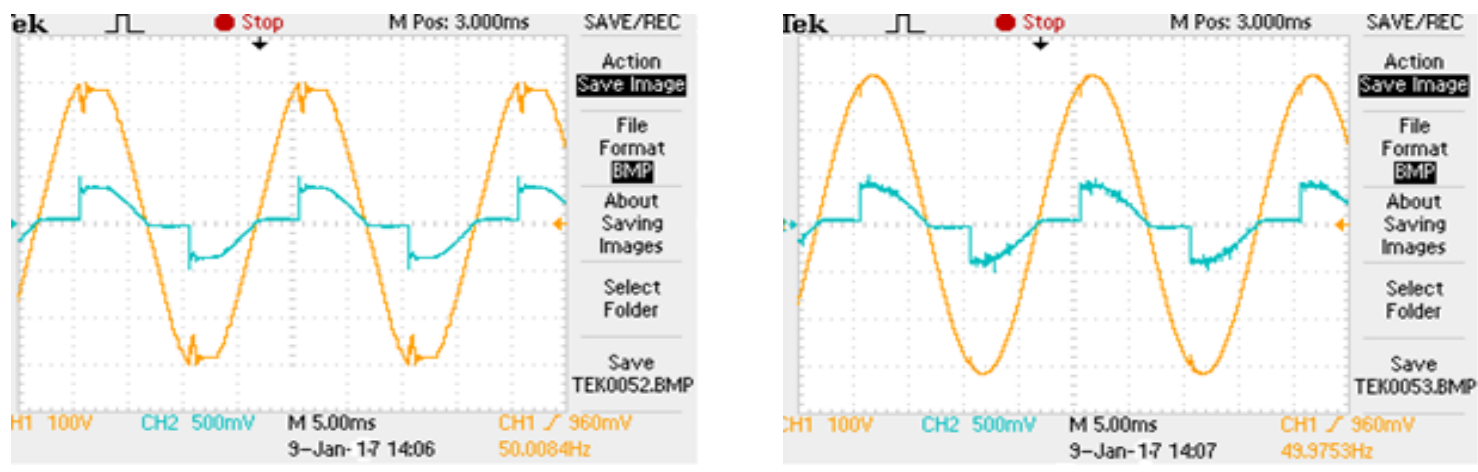

Figure 11. Results at nonlinear load-AC regulator with phase control: (a) load voltage and load current without SAPF; (b) load voltage and load current with SAPF on

\section{CONCLUSIONS}

The contribution of this study is: 1) Determining the value of the current of the higher harmonic through the capacitor of the output filter-expression (6) and Figure 4. 2) Determining the voltage ripple on the capacitor depending on its value and switching frequency-expression (14). 3) On this basis offering a methodology for designing the output $L C$ filter.

The results presented in this article make it possible to determine the parameters of the output capacitor as well as the output inductance of a series active power filter with hysteresis control. The results were confirmed by computer simulation and experimental testing and show sufficient for the practical purposes accuracy.

\section{ACKNOWLEDGEMENTS}

The author/s would like to thank the Research and Development Sector at the Technical UniversitySofia for the financial support.

\section{REFERENCES}

[1] Akagi H., "New Trends in Active Filters for Power Conditioning," IEEE Trans. On Indus., vol. 32, no. 6, pp. 1312$1322,1996$.

[2] Akagi H., "Modern active filters and traditional passive filters," Bulletin of the Polish Academy of Sciences, Technical Sciences, vol. 54, no. 3, pp. 255-269, 2006.

[3] Antchev M., "Classical and recent aspects of active power filters for power quality improvement," Classical and Recent Aspects on Power Systems Optimization, Academic Press, Elsevier, pISBN: 9780128124413, eISBN: 9780128124420, 2018. 
[4] Huann-keng Chiang, Bor-ren Lin, Kuan-wei Wu, "Series active power filter for current harmonic and load voltage compensation," Proceedings of the TENCON 2005-IEEE Region 10 Conference, DOI: 10.1109/TENCON.2005.300889

[5] Biraja Prasad Nayak, Animesh Shaw, "Reduction of harmonics and voltage sag compensation by series active power filter," Proceedings of the 2017 International Conference on Data Management, Analytics and Innovation (ICDMAI), DOI: 10.1109/ICDMAI.2017.8073485

[6] Barrero F., S. Martinez, F. Yeves and P.M. Martinez, "Active Power Filters for Line Conditioning: a Critical Evaluation,” IEEE Transactions on Power Delivery, vol. 15, no. 1, pp. 319-325, 2000.

[7] Bor_Ren L. and Y.-L. Hou, "Single-phase Integrated Power Quality Compensator Based on Capacitor-Clamped Configuration," IEEE Transactions on Industrial Electronics, vol. 49, no. 1, pp. 173-185, 2002.

[8] Chen G., Zh. Lu, Zh. Qian and F. Zh. Peng, "A New Serial Hybrid Active Power Filter Using Controllable Current Source," IEEE 33rd Annual, PESC, vol. 1, pp. 364-368, 2002.

[9] Darwish M.K, "Single-Chip Inverter for Active Filters," Electronics Letters $26^{\text {th }}$ September, vol. 38, no. 20, pp. 1159-1160, 2002.

[10] Pan Z., F.Z Peng and S. Wang, "Power Factor Correction Using a Series Active Filter," IEEE Transactions. on Power Electronics, vol. 20, no. 1, pp. 148-153, 2005.

[11] Chang G.W. and T.-Ch. Sheen, "A Comparative Study of Active Power Filter Reference Compensation Approaches," Power Engineering Society Summer Meeting, IEEE, pp. 1017-1021, vol. 2, 2002.

[12] Hernandez C., N. Varquez and V Cardenas, "Sliding Mode Control for A Single Phase Active Power Filter," Power Electronics Congress, CIEP 98. VI IEEE International, pp. 171-176, 1998.

[13] Jain S.K., P. Agrawal and H.O. Gupta, "Fuzzy Logic Controlled Shunt Active Power Filter for Power Quality Improvement," IEE Proceedings Electric Power Applications, vol. 149, no. 5, pp. 317-328, 2002.

[14] Laxmi A. J., G. T. R. Das and K. U. Rao, "Role of PI and Fuzzy Controller in Unified Power Quality Conditioner," ARPN Journal of Engineering and Applied Sciences, vol. 2, no. 2, pp. 1-10, 2007.

[15] Lan Li, Hai Chen, and Xiaoxia Cao, "Deadbeat Control Technique Applied to Active Power Filter," Informatics in Control, Automation and Robotics, Springer, vol. 2, pp. 75-83, 2019, DOI https://doi.org/10.1007/978-3-64225992-0_10.

[16] Gelan Zhu ; Gang Wang ; D. Hua , "Sliding mode control with variable structure of series active power filter," Proceedincs of the 2009 IEEE Power \& Energy Society General Meeting, Calgary, Canada, DOI: 10.1109/PES.2009.5275325

[17] Fan, X., Zhang, D., Sun, Q., et al., "Hysteresis Current Control Strategy for Three-phase Three-wire Active Power Filter," Automation of Electric Power System, vol.31, no. 18, pp. 57-60, 2007.

[18] Antchev M.H., M.P. Petkova, A.T. Kostov, "Hysteresis-current control of single-phase shunt active power filter using frequency limitation," Proceedings of the conference PES 2007, Cleanwater, USA, pp. 234-238, 2007.

[19] Jiancheng Song ; Feiyan Tian ; Yunguang Gao ; Lijun Zheng, "A composite current control method of the three phase shunt active power filter," Proceedings of the 2016 IEEE 2nd Annual Southern Power Electronics Conference (SPEC) Auckland, New Zealand, DOI: 10.1109/SPEC.2016.7846017

[20] You-hua Jiang ; Yong-wei Chen, "Neural Network Control Techniques of Hybrid Active Power Filter," Proceedings of the 2009 International Conference on Artificial Intelligence and Computational Intelligence, Shanghai, China, DOI: 10.1109/AICI.2009.296

[21] Elmitwally A., S. Abdelkader and M. El-Kateb, "Neural Network Controlled Three-Phase Four-Wire Shunt Active Power Filter," IEE Proceedings Generation Transmission and Distribution, vol. 147, no. 2, pp. 87-92, 2000.

[22] B. Gonzatti ; S. C. Ferreira ; Carlos H. da Silva ; L. E. Borges da Silva ; G. Lambert-Torres ; L. G., "FernanPLLless control strategy applied to Hybrid Active Series Power Filter," Proceedings of the 10th IEEE/IAS International Conference on Industry Applications, Fortaleza, Brazil,DOI: 10.1109/INDUSCON.2012.6453300

[23] Jingyang Fang ; Guochun Xiao ; Xu Yang ; Yi Tang , "Parameter Design of a Novel Series-Parallel-Resonant LCL Filter for Single-Phase Half-Bridge Active Power Filters," IEEE Transactions on Power Electronics, vol. 32, no. 1, 2017, DOI: 10.1109/TPEL.2016.2532961

[24] Platek, T., "Analysis of Ripple Current in the Capacitors of Active Power Filters," Energies, vol. 12, no. 4493, 2019.

[25] Copper Development Association, Voltage Disturbances, Standard EN50160-Voltage Characteristics in Public Distribution System, from https://copperalliance.org.uk/uploads/2018/03/542-standard-en-50160-voltagecharacteristics-in.pdf.

[26] Schneider Electric SA, Harmonic mitigation, Solution Handbook, June, 2009. 


\section{BIOGRAPHIES OF AUTHORS}
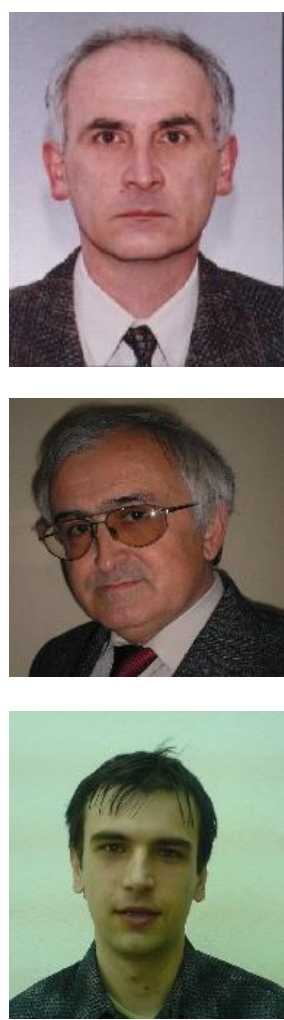

Mihail Antchev, was born in Sofia, Bulgaria, in 1955. He awarded Master degree at Technical University - Sofia, Bulgaria, Faculty of Radioelectronics, in 1981. The PhD degree received in 1990 in Industrial electronics at Technical University - Sofia. The Dsc degree received in 2010 in Elecronic converters at Technical University - Sofia. He is Professor in Power electronics, Faculty of electronic engineering and technologies, Technical University - Sofia. He works in the field of power electronic converters with improved energy indicators, as well as of dynamic and control system of power electronic converters. E-mail: antchev@tu-sofia.bg

Vanjo Gourgoulitsov, was born in Vidin, Bulgaria, in 1951. He graduated in Polytechnic Institute of Donetsk, Ukraine. The PhD degree received in 2009 in Industrial electronics at Technical University - Sofia. He is Associate professor at College of energy and electronics, Technical university - Sofia. He works in the field of power electronics, digital and microprocessor technologies, microelectronics.

E-mail: vtg_otk@abv.bg

Hristo Antchev, was born in Sofia, Bulgaria, in 1981. He awarded Master degree at Technical University - Sofia, Bulgaria in specialization "Power Electronics" in 2004. The PhD degree received in 2012 in Industrial electronics at Technical University - Sofia. He is Chief assistant at University of chemical technology and metallurgy. He works in the field of design of power electronic converters

E-mail: hristo_antchev@uctm.edu 